\title{
Green Synthesis of Gold Nanoparticles from Coprinus comatus, Agaricaceae, and the Effect of Ultraviolet Irradiation on Their Characteristics
}

\author{
Ghassan Adnan NAEEM ${ }^{1}$, Ahmed Saadoun JALOOT ${ }^{2}$, \\ Mustafa Nadhim OWAID ${ }^{2,3, *}$ and Rasim Farraj MUSLIM ${ }^{2}$ \\ ${ }^{I}$ Department of Biophysics, College of Applied Sciences-Hit, University of Anbar, Anbar 31007, Iraq \\ ${ }^{2}$ Department of Environmental Sciences, College of Applied Sciences-Hit, University of Anbar, \\ Anbar 31007, Iraq \\ ${ }^{3}$ Department of Heet Education, General Directorate of Education in Anbar, Ministry of Education, \\ Anbar 31007, Iraq
}

('Corresponding author’s e-mail: mustafanowaid@uoanbar.edu.iq, mustafanowaid@gmail.com)

Received: 19 January 2020, Revised: 24 April 2020, Accepted: 25 May 2020

\begin{abstract}
The present research aims to produce gold nanoparticles (AuNPs) from the aqueous extract of locally isolated mushroom Coprinus comatus from Hit city, Iraq. Its properties were studied using the optical vision, UV-Vis, EDX, XRD, FTIR, AFM, and Zetasizer analyses. The exposure of the colloidal solution of AuNPs to UV radiation was investigated for 1, 2, and $3 \mathrm{~h}$. The results showed the color change of the interaction mixture from light yellow to purple after $25 \mathrm{~min}$. The lambda max of the absorbance reached $530 \mathrm{~nm}$ using UV-Visible spectrum as evident in the formation of AuNPs. FTIR spectra revealed the presence of functional groups related to peptides, proteins, flavonoids, monosaccharides, and phenolic compounds, which reduced gold ions. The EDX technique showed that the formed nanoparticles were AuNPs. XRD results showed that AuNPs have a face-centered cubic (fcc) crystal. The UV irradiation at different times led to an increase in the intensity of absorbance and sizes of AuNPs from $17.39 \mathrm{~nm}$ before the irradiation and switched to 58.16, 59.13, and $47.35 \mathrm{~nm}$ after 1, 2, and 3 $\mathrm{h}$, respectively, but their sizes remained within the nanoscale range (less than $100 \mathrm{~nm}$ ). In conclusion, the best result was observed after about an hour on the effects of UV irradiation on sizes of AuNPs, which reached smaller nanoparticles compared with times 2 and $3 \mathrm{~h}$.
\end{abstract}

Keywords: AuNPs, Mycosynthesis, Shaggy mane, Ultraviolet irradiation, XRD

\section{Introduction}

Green synthesis of metallic nanoparticles is considered an ecofriendly approach. This method has been used worldwide in recent studies as nano drugs against cancers, bacterial and fungal infections, and other inflammations [1]. Mycological materials were utilized as myco-reducer to synthesize green nanoparticles, which is called myconanotechnology. Mycomaterials include purified materials such as enzymes/proteins, polysaccharides, polysaccharides protein complexes, or crude extracts such as fruiting bodies extracts, fungal mycelia extracts, and free cell filtrate. Green chemistry methods have attempted to myco-synthesize silver, gold, iron, NPs, and others using mycomaterials in different ways. The green mushroom nanoparticles were investigated as antimicrobial, antioxidant, antitumor agents [2].

The production of metallic nanoparticles from mushrooms is one of the recent studies that tend to use fruiting bodies or mycelia as a reducing agent in the formation of nanoparticles in a clean and environmentally friendly approach. This specialty lies within the biosynthesis of nanoparticles, also called 
Mycosynthesis of NPs [3]. The volume of the produced mushrooms is significant and economical in introducing this fresh food into the formation of metallic nanoparticles used for biomedical treatments [4]. The mycosynthesized gold nanoparticles from mushrooms were used as anticancer agents [5,6]. These nanoparticles also were applied in the decolorization of dyes [7]. The mycosynthesized AuNPs from mushrooms were succeeded by using few edible mushrooms, including Pleurotus sapidus [8], Pleurotus florida [5,9], Pleurotus ostreatus [7,10], Pleurotus cornucopiae [11], Lentinula edodes [12], and Flammulina velutipes [13]

Coprinus comatus (Shaggy mane) is one of the medical and edible mushrooms belonging to the family of Agaricaceae. Its extracts were used in treating Alzheimer's disease [14]. It has many medical benefits such as antibacterial [15], anticancer, anti-oxidant [16,17], hepatoprotective, anti-inflammatory [18], anti-androgenic [19], anti-diabetic [20], anti-obesity [21], and acetylcholinesterase inhibitory [22] activity. From the literature, no research used Coprinus comatus for synthesizing any metallic nanoparticles.

Hence, this study is considered the first to attempt to mycosynthesize AuNPs from the extract of Coprinus comatus fruiting bodies, and it aims to screen the influence of ultraviolet irradiation at different times on characteristics of AuNPs, and their crystalline nature.

\section{Materials and methods}

\section{Mushroom samples}

The fruiting bodies of the fungus Coprinus comatus (Shaggy mane), Agaricaceae, were collected from one of the groves of the city of Hit, Iraq. Morphological characteristics authenticated the species level as per the Atlas of mushrooms for Hall et al. [23]. The common name is which belongs to. The fungal samples were cleaned, chopped, and used in future tests to mycosynthesize gold nanoparticles (AuNPs).

\section{Extraction of Coprinus comatus fruiting bodies}

The aqueous extract was prepared by taking $30 \mathrm{~g}$ of fresh fruiting bodies of Coprinus comatus boiled $\left(10{ }^{\circ} \mathrm{C}\right)$ in $200 \mathrm{~mL}$ distilled water (DW) on the hotplate magnetic stirrer for $10 \mathrm{~min}$. Then it was filtered with filter paper (Whatman No.1) with a centrifuge at 4,000 rpm. The filtrate was used in the mycosynthesis of AuNPs. The watery extract was stored at four ${ }^{\circ} \mathrm{C}$ until using it to synthesize AuNPs.

\section{Mycosynthesis of gold nanoparticles}

Ten millimeters of the mushroom extract was mixed with $90 \mathrm{~mL}$ of $1 \mathrm{mM}$ Chloroauric acid $\left(\mathrm{HAuCl}_{4} \cdot 4 \mathrm{H}_{2} \mathrm{O}\right)$ solution (purchased from Direvo Industrial Biotechnology, Germany). The extract was left on the hotplate magnetic stirrer for $25 \mathrm{~min}$ at $80^{\circ} \mathrm{C}$ until the color changed from bright yellow to purple [12].

\section{Characterization of mycosynthesized AuNPs}

The properties of the mycosynthesized AuNPs were studied using the change in color, UV-Visible spectrum, FTIR (Bruker, Germany, Tensor 27 Model), Zetasizer, AFM (AFM model AA 3000 SPM 220 V-Angstrum Advanced INC.), XRD (Model 6000 X-Ray, SHIMADZU in Central Organization for Standardization and Quality Control, Baghdad), and EDX (Energy Dispersive X-Ray Spectroscopy, Bruker Company, Germany, X Flash 6L10 Model in Al-Nahrain University, Baghdad).

\section{The exposure to UV radiation}

Samples of the colloidal AuNPs were exposed for 1, 2, $3 \mathrm{~h}$ with the UV lamp (wavelength $256 \mathrm{~nm}$ ), at a temperature of $15^{\circ} \mathrm{C}$ [24]. The characteristics of the various samples were measured before and after they were exposed to UV radiation. FTIR and UV-Vis were achieved to see the changes in these samples. 


\section{Results and discussion}

\section{Optical vision and UV-Visible analyses}

The optical vision of the mycosynthesized AuNPs is presented in Figure 1. The mixture color of the aqueous extract of Coprinus comatus with the $\mathrm{HAuCl} 4.4 \mathrm{H} 2 \mathrm{O}$ solution $(1 \mathrm{mM})$ changed from yellow to purple after $25 \mathrm{~min}$. This change is a piece of clear evidence for the synthesis of AuNPs from the mushroom due to the behavior of these NPs in the absorption of the UV-Visible [25]. This agrees with the results of Owaid et al. [11], who mycosynthesized AuNPs from the oyster mushroom Pleurotus cornucopiae.

Moreover, it was found that the highest absorption value of colloidal gold nanoparticles occurred at the wavelength of $530 \mathrm{~nm}$ as in UV-visible spectra (Figure 1). The UV-Visible spectrum supplied Surface Plasmon Resonance phenomenon discovers for Au [26]. This experiment showed that time was an affirmative act to increase the intensity of the purple color. This increase is evidence that the rise in the heating leads to an increase in the activation energy [12] and allowed to active substances of the extract to play an essential role as a reducing agent for gold ions in the form of atoms, as mentioned by Owaid et al. [11].

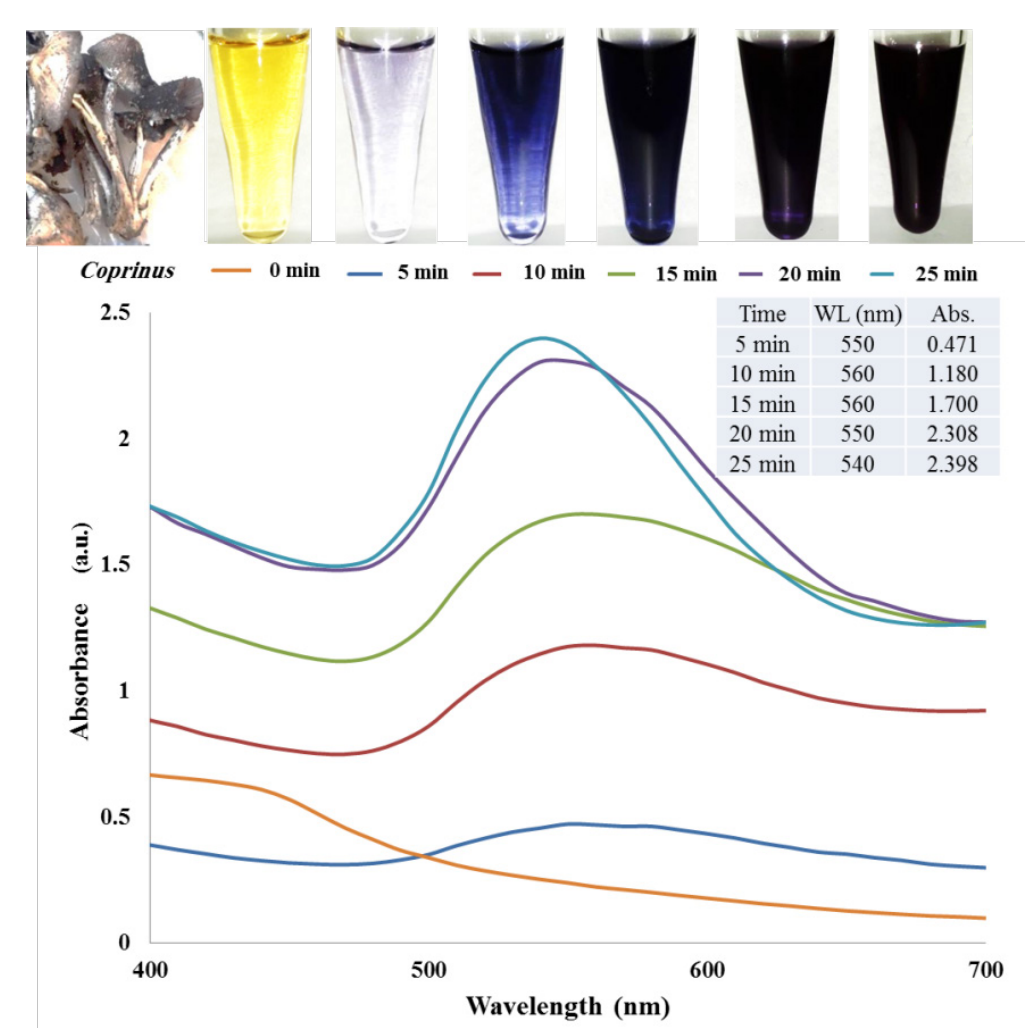

Figure 1 UV-Visible spectra of the mycosynthesized AgNPs from Coprinus comatus.

Figure 2A showed the absorption band at 1,394 $\mathrm{cm}^{-1}$. This band is due to the homogeneous bending vibration of the $-\mathrm{CH}$ group and the absorption band at 2,901 and 2,987 $\mathrm{cm}^{-1}$ are due to the homogeneous stretch vibration of the $-\mathrm{CH}$ group. In contrast, the absorption band at $1,066 \mathrm{~cm}^{-1}$ belongs to the single bond $(\mathrm{C}-\mathrm{C})$ in methylene groups $(\mathrm{CH} 2)$ and methyl groups $(\mathrm{CH} 3)$. However, all the mentioned peaks indicate the presence of Alkane compounds such as methyl $(-\mathrm{CH} 3)$ and methylene $(-\mathrm{CH} 2)$ present in the composition of monosaccharides, polysaccharides, amino acids, and fatty acids [27-30]. The broad 
http://wjst.wu.ac.th

absorption band at $3,256 \mathrm{~cm}^{-1}$ confirms the presence of a stretch vibration of the group -OH in the extract and thus confirms the finding of phenolic compounds [31], monosaccharide [18], and melanin pigment [32].

In Figure 2B, the FTIR spectrum of AuNPs is observed in the emergence of a new band that differs radically in its location at the site $1,636 \mathrm{~cm}^{-1}$ compared with Figure $2 \mathrm{~A}$ for just the mushroom extract. This band belongs to the carbonyl group $(\mathrm{C}=\mathrm{O})$, where it is believed the presence of compounds containing the amide group (NH-CO) as in peptides and proteins, as well as flavonoids, monosaccharide, and phenolic compounds [31], which covered element atoms and raised the surface area of metallic nanoparticles [24].
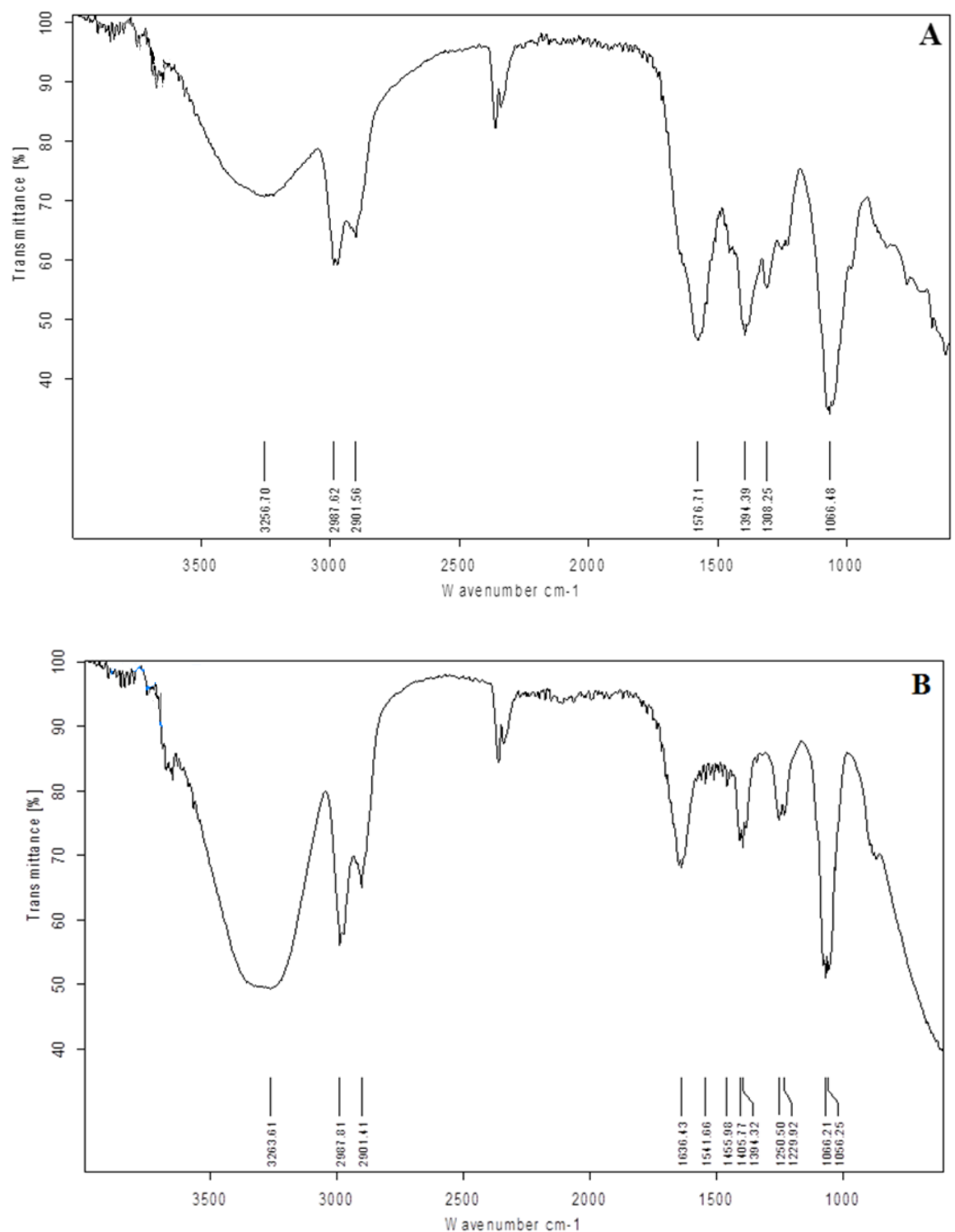

Figure 2 FTIR of the mushroom extract (a) and mycosynthesized gold nanoparticles (b). 
Figure 3 represents the specific EDX analysis of the residue resulting from the interaction of the fungus extract with the gold salt. This indicates the presence of the gold component, which comes from AuNPs [11]. Generally, Figure 3 also shows the presence of carbon, nitrogen and oxygen, due to the various organic compounds such as amino acids, fatty acids, and polyphenols present in the Coprinus comatus extract $[18,30]$. Also, the peak of chlorine may be a noise peak especially at $0 \mathrm{keV}$ caused by the noise of the electronics of the detector of EDX device. However, sulfur is related with some amino acids types $[33,34]$ and phosphorus is related to their high amounts in this mushroom [35,36]. The FTIR after 2 and $3 \mathrm{~h}$ did not show any significant alters in the peaks thus their images did not include here.

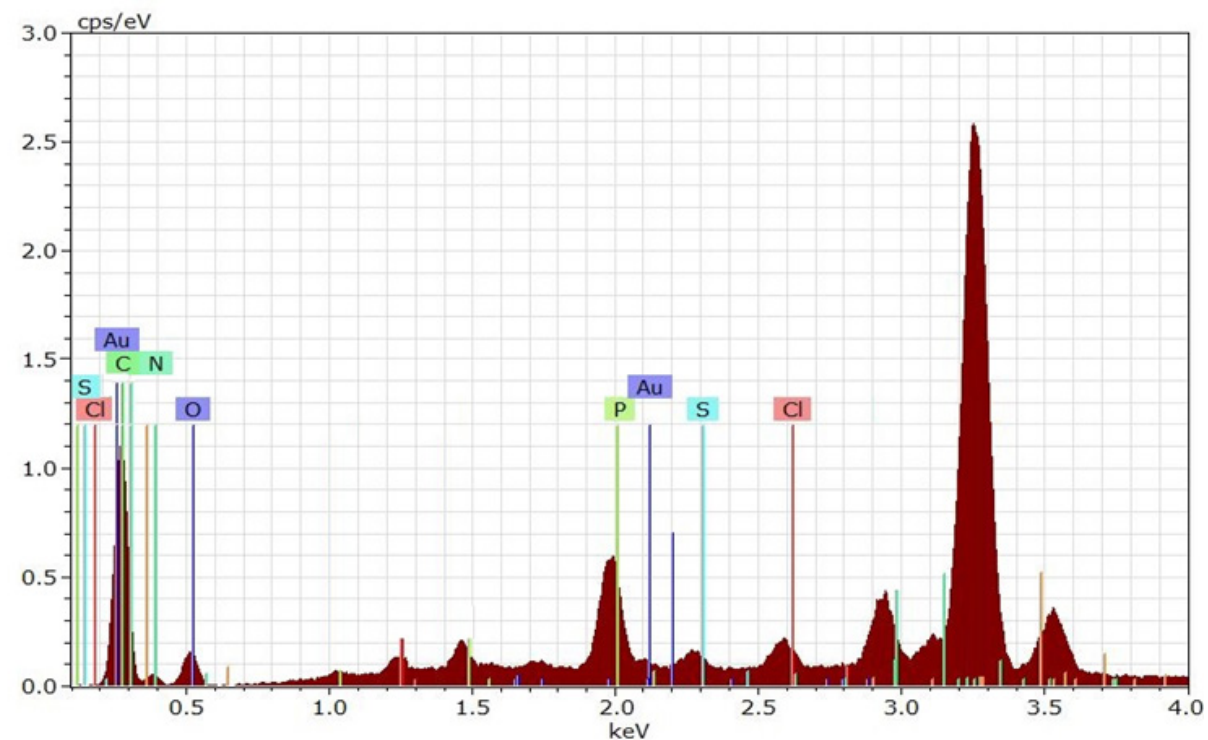

Figure 3 EDX of the mycosynthesized gold nanoparticles using Coprinus comatus.

Table 1 Amplitude, hybrid and functional parameters of gold nanoparticles with and without UV irradiation.

\begin{tabular}{lcccc}
\hline \multicolumn{1}{c}{ Parameters } & \multicolumn{4}{c}{ Time of UV Irradiation } \\
\hline Amplitude parameters & $\mathbf{0 ~ h}$ & $\mathbf{1 ~ h}$ & $\mathbf{2 ~ h}$ & $\mathbf{3 ~ h}$ \\
Roughness average (Sa) & $0.997 \mathrm{~nm}$ & $1.67 \mathrm{~nm}$ & $1.25 \mathrm{~nm}$ & $2.87 \mathrm{~nm}$ \\
Root mean square (Sq) & $1.17 \mathrm{~nm}$ & $1.92 \mathrm{~nm}$ & $1.46 \mathrm{~nm}$ & $3.34 \mathrm{~nm}$ \\
Ten-point height (Sz) & $4.46 \mathrm{~nm}$ & $6.60 \mathrm{~nm}$ & $5.29 \mathrm{~nm}$ & $6.76 \mathrm{~nm}$ \\
Hybrid parameters & & & & \\
Root mean square slope (Sdq) & $0.138 \mathrm{~nm}^{-1}$ & $0.34 \mathrm{~nm}^{-1}$ & $0.16 \mathrm{~nm}^{-1}$ & $0.331 \mathrm{~nm}^{-1}$ \\
Mean summit curvature (Ssc) & $-0.0155 \mathrm{~nm}^{-1}$ & $-0.0263 \mathrm{~nm}^{-1}$ & $-0.0214 \mathrm{~nm}^{-1}$ & Non-detected \\
Surface area ratio (Sdr) & 0.908 & 5.27 & 1.21 & 4.64 \\
Functional parameters & & & & \\
Reduced summit height (Spk) & $0.346 \mathrm{~nm}^{\mathrm{n}}$ & $0.742 \mathrm{~nm}$ & $0.491 \mathrm{~nm}$ & $0.223 \mathrm{~nm}$ \\
Core roughness depth (Sk) & $3.56 \mathrm{~nm}$ & $5.76 \mathrm{~nm}$ & $4.61 \mathrm{~nm}$ & $11.20 \mathrm{~nm}$ \\
Reduced valley depth (Svk) & $0.521 \mathrm{~nm}$ & $0.15 \mathrm{~nm}$ & 0.178 & $1.47 \mathrm{~nm}$ \\
\hline
\end{tabular}


Figure 4 illustrates 4 images (A, B, C and D) of Atomic Force Microscope (AFM) including the lateral (2D) and Figure 5 (A, B, C and D) shows 4 images of 3D (3-dimensional) that exhibit surface roughness of the mycosynthesized AuNPs at size images $1,618 \times 1,610,1,654 \times 1,615,1641 \times 1594$ and $1605 \times 1535 \mathrm{~nm}^{2}$ for AuNPs before UV irradiation (A) and AuNPs after 1, 2 and $3 \mathrm{~h}$ from UV irradiation (B, C and D), respectively. Surface roughness analysis exhibits various parameters like amplitude, hybrid and functional parameters, as in Table 1.

However, amplitude parameters had measured such as roughness average reach to $0.997 \mathrm{~nm}$ before UV irradiation and increased to $1.67,1.25$, and $2.87 \mathrm{~nm}$ after UV irradiation for times 1,2 , and $3 \mathrm{~h}$, respectively. Hybrid parameters had measured, such as surface area ratio, which reached 0.908 before UV irradiation and increased to 5.27, 1.21, and 4.64 after UV irradiation for times 1, 2, and $3 \mathrm{~h}$, respectively. Moreover, functional parameters had measured like core roughness depth recorded $3.56 \mathrm{~nm}$ before UV irradiation and increased to 5.76, 4.61, and $11.20 \mathrm{~nm}$ after UV irradiation for times 1,2 , and $3 \mathrm{~h}$, respectively. This is an indicator to form gold nanoparticles in a small size with an average reached 49.68, 64.43, and $54.16 \mathrm{~nm}$, respectively, but they stay less than $100 \mathrm{~nm}$, as in Figure 6. These findings agree with Owaid et al. [24], especially for the Cumulation of AuNPs. After one $\mathrm{h}$, the best results were observed about the effect of UV irradiation on sizes of AuNPs, which reached smaller nanoparticles compared with times 2 and $3 \mathrm{~h}$, and this agreed with the results of Watcharaporn et al. [37]. In this study, only one $\mathrm{h}$ instead of more than three $\mathrm{h}$ was best to enhance small sizes of AuNPs but close of sizes of AuNPs without UV irradiation, as shown in Figures 4, 5, and 6. Furthermore, that leads to enhancing the properties of retention and dissolution of AuNPs to enhance gold ions release [38], and that may be exploited for reducing effects of UV on human cells by AuNPs [39]. Figure 6 showed a range of granularity Cumulation Distribution ranged from 38 - $83 \mathrm{~nm}$ before UV irradiation and changed to 25 45, 38 - 142 and $43-73 \mathrm{~nm}$ after 1, 2, and $3 \mathrm{~h}$ from UV irradiation, respectively.
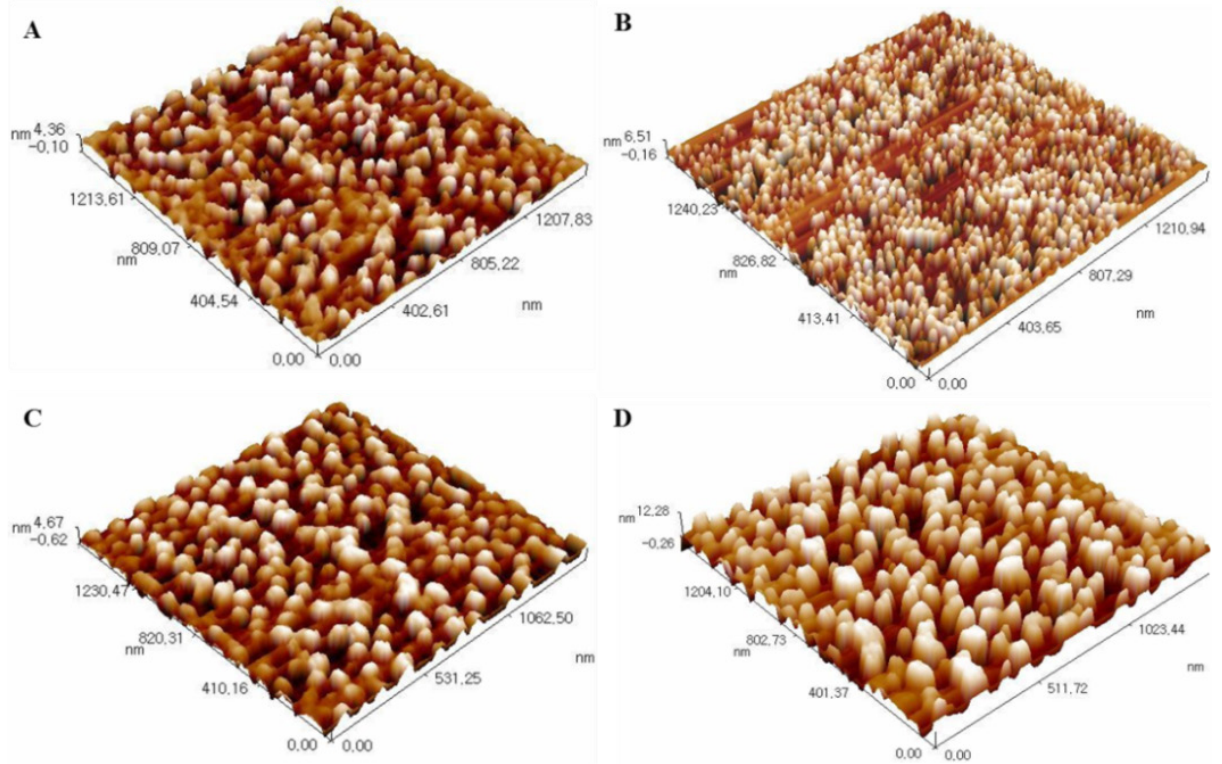

Figure 4 AFM of AuNPs, 3-dimensional A: AuNPs before UV irradiation, B, C, D: AuNPs after 1, 2 and $3 \mathrm{~h}$ from UV irradiation, respectively. 

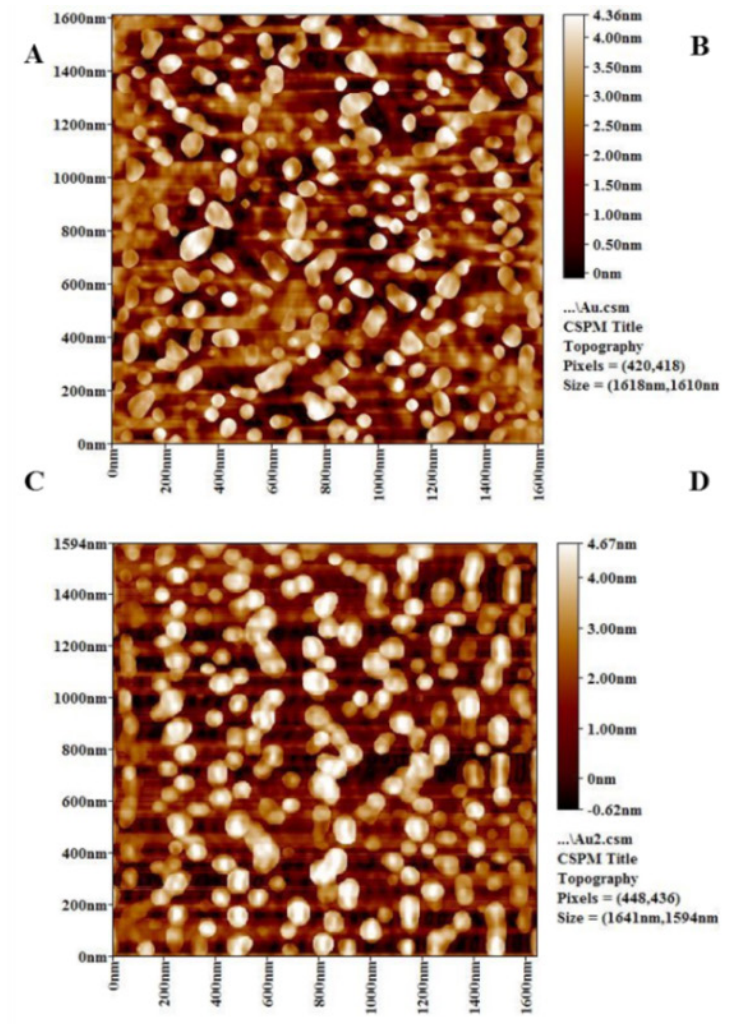
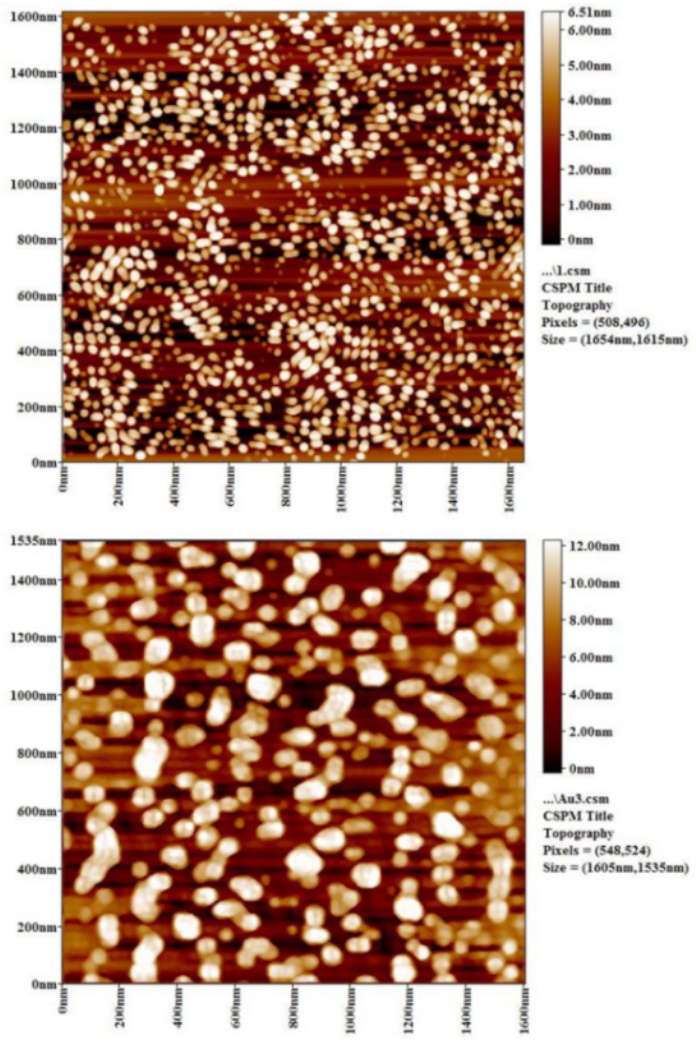

Figure 5 AFM of AuNPs, lateral dimensional.
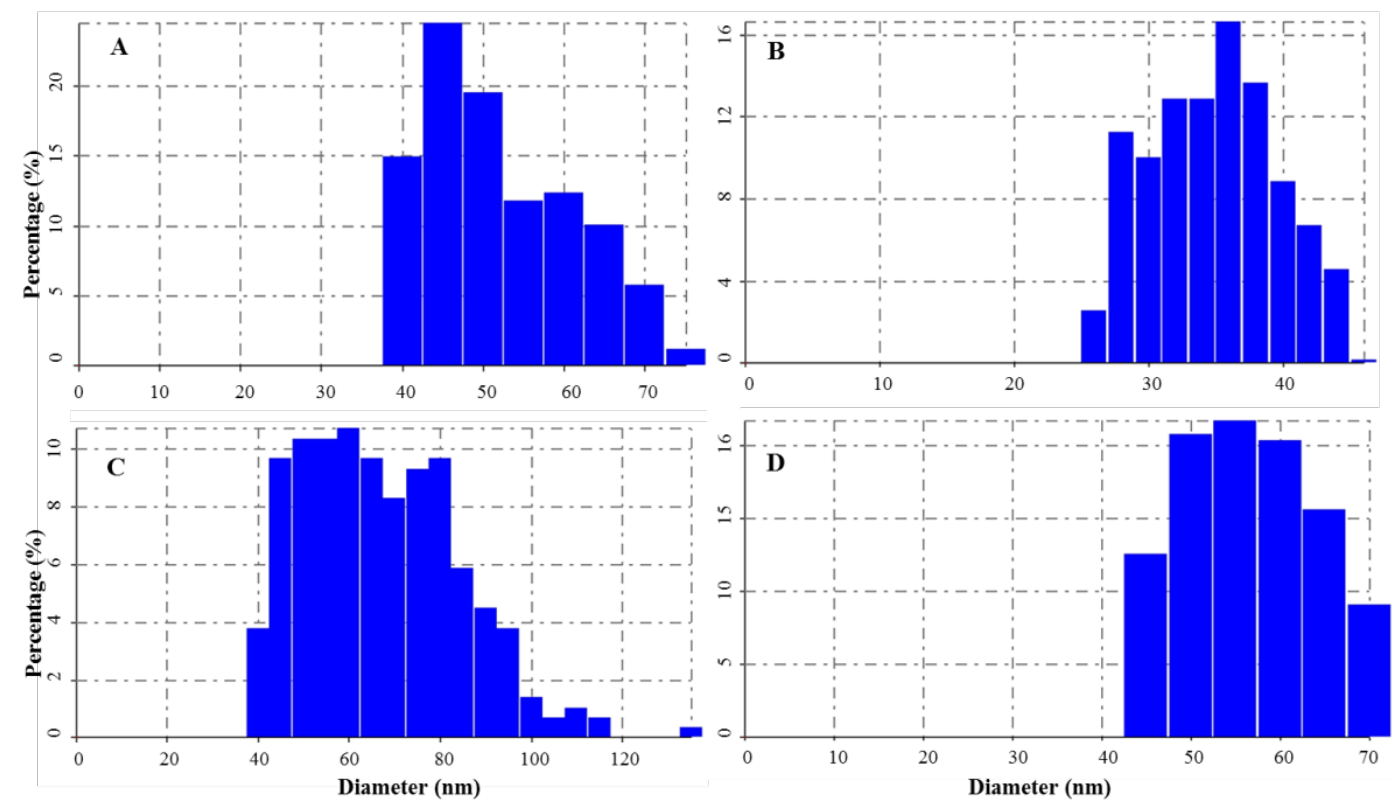

Figure 6 Histogram of granularity Cumulation Distribution of AuNPs. 
Figure 7 shows the XRD pattern of nanoparticles before UV irradiation at $2 \theta$ values ranging from $30^{\circ}$ to $80^{\circ}$; it can be seen that 4 peaks $(38.76,44.91,65.14$ and 77.51$)$. All these diffraction peaks correspond to the diffraction planes (111), (200), (220) and (311), respectively, were indexed to the gold metal with face-centered cubic ( $\mathrm{fcc}$ ) structure. This indicates that the precipitation consists of pure crystalline gold according to (International Center for Diffraction Data, ICDD No 4-0783). This is also consistent with previous studies [12]. The Lattice constant is $\mathrm{a}=4.05 \AA$ in good agreement with the standard diffraction pattern of cubic gold metal. From the XRD pattern, a powerful Brag reflection of level (111) is observed, and the average particle size D is estimated using the Debye-Scherrer equation and the calculated $\mathrm{D}$ value of reflection is $111.39 \mathrm{~nm}$.

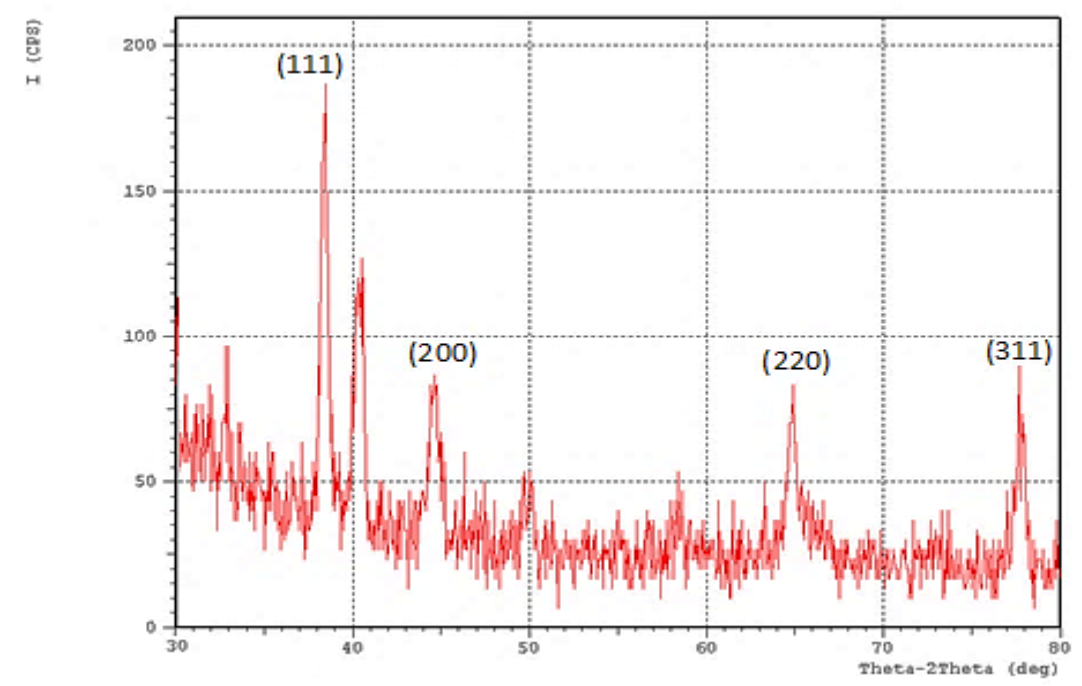

Figure 7 The XRD pattern of nanoparticles before UV irradiation.

Figures 8 - 10 represented UV-visible and XRD diffraction patterns of Au nanoparticles after UV irradiation for different times ( $3 \& 2 \mathrm{~h}$, one h). UV-visible spectra showed the highest peak was constant, which reached $550 \mathrm{~nm}$, but the optical intensity of lambda max changed for 2.398 before UV irradiation to $2.442,2.455$, and 2.434 (a.u.) after 1, 2, and $3 \mathrm{~h}$ from UV irradiation and that agree with Gasperini et al. [40]. They reported that UV irradiation increased the optical density. The crystallite size D of reflection (111) for each figure increased to 58.16, 59.13, and $47.35 \mathrm{~nm}$ after 1,2 , and $3 \mathrm{~h}$ from UV irradiation. Also, it can be observed that the irradiation of nanoparticles by ultraviolet at different times $(1,2$, and $3 \mathrm{~h}$ ) reduces the height of X-ray intensity peaks from crystalline levels (111), (200), (220), and (311), except for the 2-hour radiation period (Figure 9), we again observe the peaks of the intensity of the reflection of crystalline levels due to the effect of UV radiation, like ionizing radiation, on the electron distribution in crystals. As a result of the response of electrons to the high frequencies of ultraviolet waves, the material's electronic structure is destroyed because electrons move from lower energy levels to higher energy levels [41]. Also, the intensity of absorbance showed an increase with UV irradiation compared without the irradiation, as in Figures 8,9, and 10, and that agreed with Watcharaporn et al. [37]. 

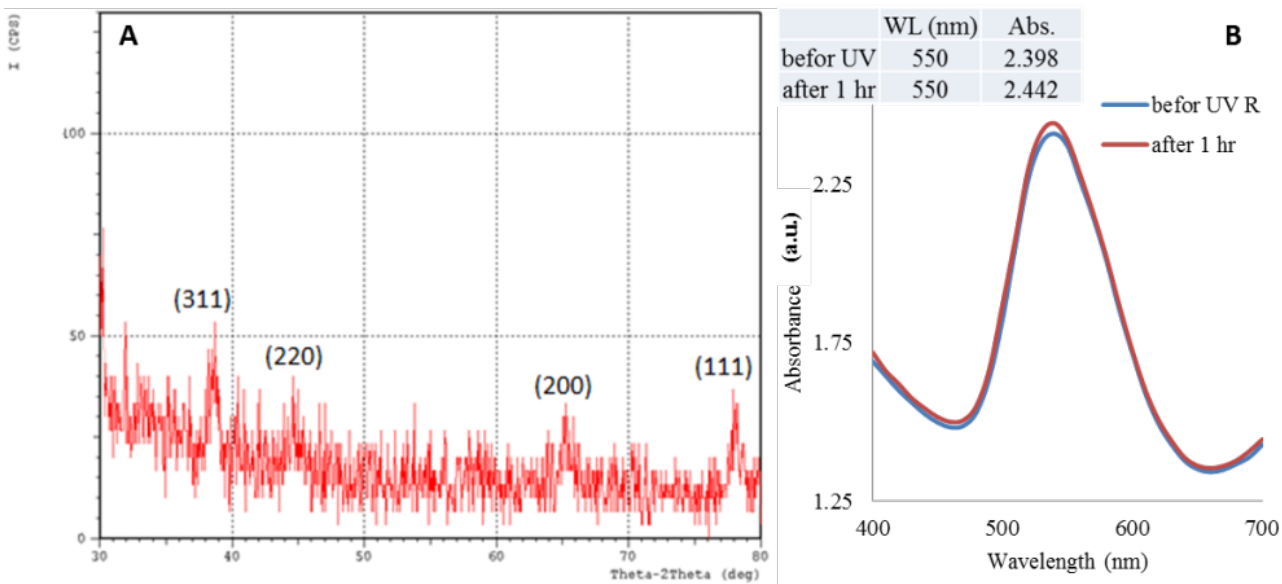

Figure 8 XRD and UV-Vis analyses for AuNPs after UV irradiation for $1 \mathrm{~h}$.
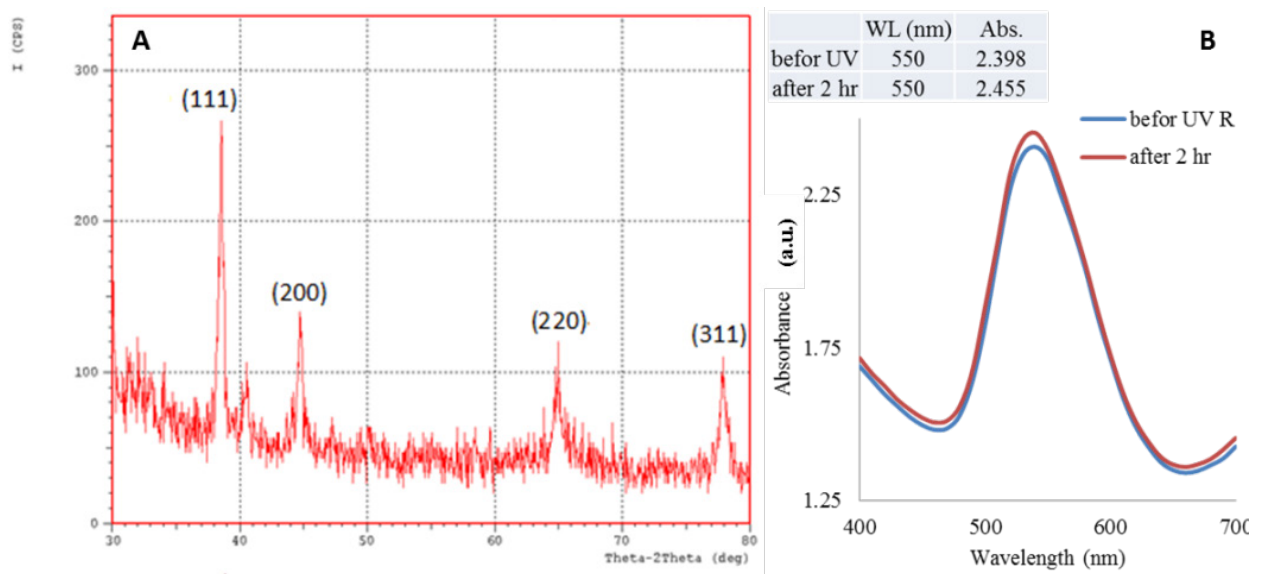

Figure 9 XRD and UV-Vis analyses for AuNPs after UV irradiation for $2 \mathrm{~h}$.
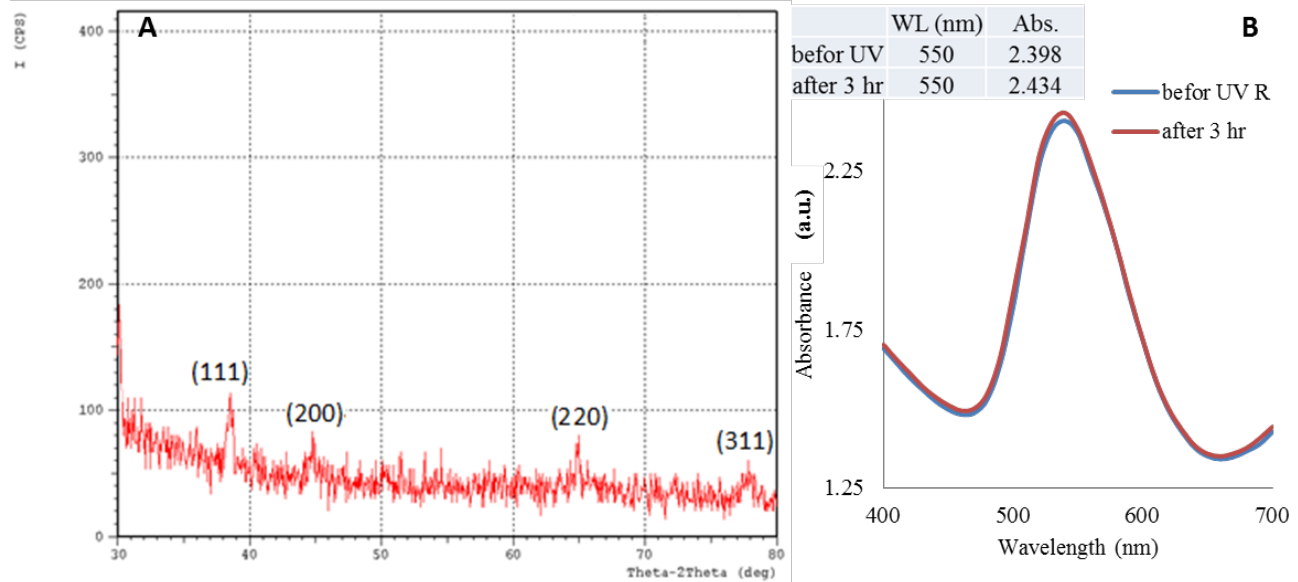

Figure $10 \mathrm{XRD}$ and UV-Vis analyses for AuNPs after UV irradiation for $3 \mathrm{~h}$. 
However, Table 2 exhibits the crystallite size D of reflection (111) each time. The nanoparticles' average size increases when these particles are exposed to ultraviolet waves, but their size remains within the nanoscale range of fewer than 100 nanometers. The size of AuNPs was $17.39 \mathrm{~nm}$ before UV irradiation and increased to 58.16, 59.13, and $47.35 \mathrm{~nm}$ after 1,2 , and $3 \mathrm{~h}$ from UV irradiation. The surface plasmodium oscillation of surface gold nanoparticles, which becomes heterogeneous with the rest of the particles, makes it a nucleus to accumulate more gold nanoparticles. This increases the proportion of NPs in the colloidal solution and increases the particle size, which agrees with the results of parameters of roughness surface in AFM, as in Table 1.

Table 2 The average particle size of D for AuNPs before and after exposure to UV.

\begin{tabular}{ccccccc}
\hline $\begin{array}{c}\text { Time of UV } \\
\text { Irradiation }\end{array}$ & $\mathbf{2 \theta}$ & $\mathbf{C o s} \boldsymbol{\theta}$ & $\mathbf{d}$ & $\begin{array}{c}\mathbf{a} \\
(\stackrel{\mathbf{A}}{)}\end{array}$ & FWHM & D (nm) \\
\hline $0 \mathrm{~h}$ & 38.4055 & 0.9443 & 2.34196 & 4.05 & 0.4839 & 17.39 \\
$1 \mathrm{~h}$ & 38.8220 & 0.9431 & 3.17495 & 5.49 & 0.1449 & 58.16 \\
$2 \mathrm{~h}$ & 38.5424 & 0.9439 & 3.17380 & 5.48 & 0.1424 & 59.13 \\
$3 \mathrm{~h}$ & 38.5424 & 0.9440 & 2.33504 & 4.03 & 0.1778 & 47.35 \\
\hline
\end{tabular}

\section{Conclusions}

This research is considered the 1st attempt to mycosynthesize AuNPs from the extract of Coprinus comatus fruiting bodies, and it aims to screen the influence of ultraviolet irradiation at different times on characteristics of AuNPs, and their crystalline nature. The present research results showed that the color change of the mixture from light yellow to purple after $25 \mathrm{~min}$ and the lambda max of the absorbance reached $530 \mathrm{~nm}$ using the UV-Visible spectrum, which is evidence of the formation of AuNPs from the extract of Coprinus comatus. The FTIR spectra revealed active groups like carbonyl group $(\mathrm{C}=\mathrm{O})$ and a hydroxyl group (-OH), belonging to the peptides, proteins, flavonoids, monosaccharides, polysaccharides, and phenolic compounds. The EDX technique showed that the formed nanoparticles were AuNPs with C, $\mathrm{H}, \mathrm{N}$, and $\mathrm{S}$ elements due to the amino acid composition and the organic matter of the mushroom. XRD results showed that gold nanoparticles have a face-centered cubic (fcc) crystal and that the UV irradiation at different times increased the intensity of absorbance and sizes of NPs from $17.39 \mathrm{~nm}$ AuNPs before the irradiation and switched to $58.16,59.13$, and $47.35 \mathrm{~nm}$ after 1,2 , and $3 \mathrm{~h}$, respectively, but their sizes remained within the nanoscale range (less than $100 \mathrm{~nm}$ ). Finally, the best result was observed after one $\mathrm{h}$ about the effect of UV irradiation on sizes of AuNPs, which reached smaller nanoparticles compared with times 2 and $3 \mathrm{~h}$.

\section{Acknowledgements}

The authors would like to thank the Department of Biophysics, College of Applied Sciences-Hit at University of Anbar (Iraq) for achieving this Research Project No. 16/5 on $15^{\text {th }}$ Oct 2018.

\section{References}

[1] MN Owaid. Silver nanoparticles as unique nano-drugs. In: AM Grumezescu and V Grumezescu (Eds.). Materials for biomedical engineering: Bioactive materials, properties and applications. Elsevier, 2019, p. 545-80.

[2] MN Owaid. Biomedical applications of nanoparticles synthesized from mushrooms. In: J Patra, L Fraceto and GCE Das (Eds.). Green nanoparticles nanotechnology in the life sciences. Springer Nature Switzerland AG, 2020, p. 289-303.

[3] MN Owaid and IJ Ibraheem. Mycosynthesis of nanoparticles using edible and medicinal mushrooms. Eur. J. Nanomedicine. 2017; 9, 5-23. 
http://wjst.wu.ac.th

[4] MN Owaid. Green synthesis of silver nanoparticles by Pleurotus (oyster mushroom) and their bioactivity: Review. J. Environ. Nanotechnol. Monit. Manag. 2019; 12, 100256.

[5] R Bhat, VG Sharanabasava, R Deshpande, U Shetti, G Sanjeev and A Venkataraman. Photo-biosynthesis of irregular shaped functionalized gold nanoparticles using edible mushroom Pleurotus florida and its anticancer evaluation. J. Photochem. Photobiol. B Biol. 2013; 125, 63-9.

[6] J Raman, H Lakshmanan, P John, C Zhijian, V Periasamy, P David, M Naidu and V Sabaratnam. Neurite outgrowth stimulatory effects of myco synthesized auNPs from Hericium erinaceus (Bull.: Fr.) Pers. on pheochromocytoma (Pc-12) cells. Int. J. Nanomedicine. 2015; 10, 5853-63.

[7] AI El-Batal, NM Elkenawy, AS Yassin and MA Amin. Laccase production by pleurotus ostreatus and its application in synthesis of gold nanoparticles. Biotechnol. Rep. 2015; 5, 31-9.

[8] J Sarkar, S Kalyan, A Laskar, D Chattopadhyay and K Acharya. Bioreduction of chloroaurate ions to gold nanoparticles by culture filtrate of Pleurotus sapidus Quel. Mater. Lett. 2013; 92, 313-6.

[9] I Sen, K Maity and SS Islam. Green synthesis of gold nanoparticles using a glucan of an edible mushroom and study of catalytic activity. Carbohydr. Polym. 2013; 91, 518-28.

[10] EP Vetchinkina, EA Loshchinina, AM Burov and VE Nikitina. Bioreduction of gold (iii) ions from hydrogen tetrachloaurate to the elementary state by edible cultivated medicinal xylotrophic Basidiomycetes belonging to various systematic groups and molecular mechanisms of gold nanoparticles biological synthesis. Sci. Pract. J. Heal. Life. Sci. 2013; 4, 51-6.

[11] MN Owaid, SSS Al-Saeedi and IA Abed. Biosynthesis of gold nanoparticles using yellow oyster mushroom Pleurotus cornucopiae var. citrinopileatus. Environ. Nanotechnol. Monit. Manag. 2017; 8, 157-62.

[12] MN Owaid, MA Rabeea, A Abdul Aziz, MS Jameel and MA Dheyab. Mushroom-assisted synthesis of triangle gold nanoparticles using the aqueous extract of fresh Lentinula edodes (shiitake), Omphalotaceae. Environ. Nanotechnol. Monit. Manag. 2019; 12, 100270.

[13] MA Rabeea, MN Owaid, AA Aziz, MS Jameel and MA Dheyab. Mycosynthesis of gold nanoparticles using the extract of Flammulina velutipes, Physalacriaceae, and their efficacy for decolorization of methylene blue. J. Environ. Chem. Eng. 2020; 2020, 103841.

[14] B Pejin, K Tešanović, D Jakovljević, S Kaišarević, M Rašeta, M Karaman, B Pejin, K Tešanović, D Jakovljević and S Kaišarević. The polysaccharide extracts from the fungi Coprinus comatus and Coprinellus truncorum do exhibit AChE inhibitory activity. Nat. Prod. Res. 2017; 6419, 1-5.

[15] MP de Carvalho, G Gulotta, MW do Amaral, H Lünsdorf, F Sasse and WR Abraham. Coprinuslactone protects the edible mushroom Coprinus comatus against biofilm infections by blocking both quorum-sensing and MurA. Env. Microbiol. 2016; 18, 4254-64.

[16] P Zhang, Li K, G Yang, C Xia, JE Polston, Li G, S Li and Z Lin. Cytotoxic protein from the mushroom Coprinus comatus possesses a unique mode for glycan binding and specificity. Proc. National Acad. Sci. 2017; 114, 8980-5.

[17] B Emsen and B Guven. All aspects of plant biology activities of two edible macrofungi, Coprinus comatus and Leucoagaricus leucothites in human lymphocytes: Cytogenetic and biochemical study. Plant. Biosyst. 2019; 154, 361-8.

[18] H Zhao, H Li, Q Lai, Q Yang, Y Dong, X Liu, W Wang, J Zhang and L Jia. Antioxidant and hepatoprotective activities of modified polysaccharides from Coprinus comatus in mice with alcohol-induced liver injury. Int. J. Biol. Macromol. 2019; 127, 476-85.

[19] N Dotan, SP Wasser and J Mahajna. The Culinary: Medicinal mushroom Coprinus comatus as a natural antiandrogenic modulator. 2015; 10, 148-59.

[20] G Zhou and C Han. The co-effect of vanadium and fermented mushroom of Coprinus comatus on glycaemic metabolism. Biol. Trace. Elem. Res. 2008; 124, 20-7.

[21] HJ Park, J Yun, SH Jang, SN Kang, BS Jeon, YG Ko, HD Kim, CK Won, GS Kim and JH Cho. Coprinus comatus cap inhibits adipocyte differentiation via regulation of PPAR $\mathrm{c}$ and Akt signaling pathway. PLoS One 2014; 9, e105809.

[22] A Basiri, V Murugaiyah, H Osman and R Suresh. An expedient, ionic liquid mediated multicomponent synthesis of novel piperidone grafted cholinesterase enzymes inhibitors and their molecular modeling study. Eur. J. Med. Chem. 2013; 67, 221-9. 
http://wjst.wu.ac.th

[23] IR Hall, SL Stephenson, PK Buchanan, W Yun and ALJ Cole. Edible and poisonous mushrooms of the world. Colorcraft, Hong Kong, 2003.

[24] MN Owaid, GA Naeem, RF Muslim and RS Oleiwi. Synthesis, characterization and antitumor efficacy of silver nanoparticle from Agaricus bisporus pileus, Basidiomycota. Walailak J. Sci. Technol. 2020; 17, 75-87.

[25] MI Sriram, K Kalishwaralal and S Gurunathan. Biosynthesis of silver and gold nanoparticles. In: M Soloviev (Ed.). Nanoparticles in biology and medicine, methods and protocols. Humana Press, London, 2012, p. 33-44.

[26] P Singh, Y Kim and D Yang. A strategic approach for rapid synthesis of gold and silver nanoparticles by Panax ginseng leaves. Artif. Cell Nanomed. B 2016; 44, 1949-57.

[27] D Philip. Biosynthesis of $\mathrm{Au}, \mathrm{Ag}$ and $\mathrm{Au}-\mathrm{Ag}$ nanoparticles using edible mushroom extract. Spectrochim Acta A Mol. Biomol. Spectrosc. 2009; 73, 374-81.

[28] R Bhat, R Deshpande, SV Ganachari, DS Huh and A Venkataraman. Photo-irradiated biosynthesis of silver nanoparticles using edible mushroom Pleurotus florida and their antibacterial activity studies. 2011; 2011, 650979.

[29] AH Bae, M Numata, S Yamada and S Shinkai. New approach to preparing one-dimensional Au nanowires utilizing a helical structure constructed by schizophyllan. New J. Chem. 2007; 31, 61822.

[30] J Ren, J Shi, C Han, Z Liu and J Guo. Isolation and biological activity of triglycerides of the fermented mushroom of Coprinus comatus. BMC Complement. Altern. Med. 2012; 12, 52.

[31] K Tesanovic, B Pejin, F Sibul, M Milan, M Raseta, L Janjusevic and M Karaman. A comparative overview of antioxidative properties and phenolic profiles of different fungal origins: Fruiting bodies and submerged cultures of Coprinus comatus and Coprinellus truncorum. J. Food. Sci. Technol. 2017; 54, 430-8.

[32] C Saiz-Jimenez. The chemical nature of the melanins from Coprinus spp. Soil Sci. 1983; 136, 6574.

[33] H Xiao, Y Bian, H Huang, Z Zhang, L Wu and L Wu. Inhibitory effect of protein Y3 from Coprinus comatus on tobacco mosaic virus. Pestic. Biochem. Physiol. 2019; 168, 104474.

[34] SY Tsai, HL Tsai and JL Mau. Nonvolatile taste components of fruit bodies and mycelia of shaggy ink cap mushroom Coprinus comatus (O.F. Müll.: Fr.) Pers. (Agaricomycetideae). Int. J. Med. Mushrooms 2007; 9, 47-55.

[35] G Tel, H Çavdar, E Deveci, M Öztürk, ME Duru and A Turkoğlu. Minerals and metals in mushroom species in Anatolia. Food Addit. Contam. B Surveill. 2014; 7, 226-31.

[36] A Winterboer, A Eicker and AS Wehmeyer. A preliminary report on the nutrient content of Coprinus comatus. South African J. Bot. 1983; 2, 83-4.

[37] K Watcharaporn, M Opaprakasit and V Pimpan. Effects of UV radiation and pH of tannic acid solution in the synthesis of silver nanoparticles. Adv. Mater. Res. 2014; 911, 110-14.

[38] AM Mittelman, JD Fortner and KD Pennell. Effects of ultraviolet light on silver nanoparticle mobility and dissolution. Environ. Sci. Nano. 2015; 2, 683-91.

[39] L Calzolai, S Laera, G Ceccone, D Gilliland, R Hussain, G Siligardi and F Rossi. Gold nanoparticles' blocking effect on UV-induced damage to human serum albumin. J. Nanoparticle Res. 2013; 15, 1412 .

[40] AE Gasperini, S Sanchez, AL Doiron, M Lyles and GK German. Non-ionising UV light increases the optical density of hygroscopic self assembled DNA crystal films. Sci. Rep. 2017; 7, 1-10.

[41] H Zhu, X Chen, Z Zheng, X Ke, E Jaatinen, J Zhao, C Guo, T Xie and D Wang. Mechanism of supported gold nanoparticles as photocatalysts under ultraviolet and visible light irradiation. Chem. Commun. 2009; 48, 7524-6. 